\title{
Are glass fibres carcinogenic to man? A critical appraisal
}

\author{
JAMES MILNE \\ Industrial Hygiene Division, 5 Parliament Place, Melbourne 3002, Victoria, Australia
}

In an editorial entitled 'Fiber carcinogenesis: is asbestos the only hazard?', Stanton (1974) drew attention to the possibility that inhaled fibres other than asbestos, and in particular glass fibres, could be carcinogenic to humans. The hypothesis was based on experiments carried out on rats. Specially-bred experimental animals were subjected to intrapleural application of large numbers of specially-milled glass fibres with dimensions of the order of $20 \mu \mathrm{m}$ or greater in length and less than $3 \mu \mathrm{m}$ in diameter. Similar experiments were carried out using other substances including three types of asbestos. Later, when these animals had been killed, Stanton observed the development of a high percentage of pleural tumours (mesotheliomata). Such tumours have been found to occur in humans occupationally exposed to asbestos, particularly crocidolite or blue asbestos. Stanton infers that fibreglass may therefore similarly represent an occupational hazard as a human carcinogen. He relates the alleged carcinogenicity of glass fibre to its fibrous nature (Stanton and Wrench, 1972).

The hypothesis that fibreglass may be an inhaled human carcinogen because of its fibrous nature can be questioned for several reasons:

1. To compare the results of experiments carried out on one animal species with those of another can lead to fallacious conclusions; for example, mesothelioma of the human pleura, when it does occur occupationally in asbestos workers, is closely connected with exposure to crocidolite. Other forms of asbestos such as chrysotile and amosite have been found to induce occupational tumours very rarely. Nevertheless these minerals are fibrous, and past occupational exposures have been heavy. The fibrous state therefore seems to be unrelated to human mesothelioma caused by asbestos, and Stanton's findings with rats do not discriminate between the three sorts of asbestos.

2. The route of application of the specially-milled glass fibres and their site of lodgement in the experimental animal (that is, by opening the chest wall and applying them over a large area of the pleura) is artificial. It cannot be duplicated in vivo and it has no relationship with human exposure or animal inhalation. It has been shown by Gross et al. (1970) that in rats and hamsters subjected to inhalation of exceedingly high concentrations (100 $\mathrm{mg} / \mathrm{m}^{3}$ ) of glass fibres, with mean diameter $0.5 \mu \mathrm{m}$ and length ranging from $5 \mu \mathrm{m}$ to $20 \mu \mathrm{m}$, such fibres were cleared almost completely from the parenchyma with no interstitial fibrosis. There was no evidence that the glass fibres reached the pleural cavity.

3. The applied pleural doses used by Stanton were very much larger than could possibly occur in occupational exposure. The type of glass fibre occurs only rarely, and in minute amounts.

4. (a) Asbestos fibres are found rarely in the pleura itself or within the pleural cavity in human mesothelial tumours. This finding suggests that action occurs some distance from the site in the lung parenchyma of the inhaled asbestos fibres. This action could not therefore be directly based on a physical characteristic such as fibrous shape.

(b) The artificial introduction of long, thin glass fibres into the pleural cavity ensures their retention at that site for a much longer period than would have occurred had the fibres been inhaled or otherwise deposited in the lung parenchyma where the pulmonary clearance mechanisms operate. Such fibres would have a very large surface area per unit weight, and thus allow increased biochemical activity 
compared with shorter thicker fibres. The very short fibres would easily be removed by phagocytosis and should present less carcinogenic risk by virtue of chemical or physical characteristics, as Stanton found.

5. It is important to look at the situation in cases in which man is exposed to occupational inhalation of glass fibres. It is logical to assume that any hazard to the general public would be considerably magnified under occupational conditions. There is no evidence to indicate that the health of workmen is affected detrimentally by such exposure.

Surveys of workmen in the industry (Wright, 1968) have shown no significant changes in chest radiographs. Hill et al. (1973) showed that respiratory function was unimpaired if judged by sputum production and a battery of ventilatory function tests, namely peak expiratory flow, forced vital capacity, and forced expiratory volume at one second.

The study by Wright (1968) encompassed 1389 workers who had exposures to glass fibre ranging from 10 to 25 years. Hill et al. (1973) compared 70 workers with a mean of $\mathbf{1 9 . 8 5}$ years in the industry with a control group, matched for age, sex, height, weight, and place of residence, but with no exposure to glass fibres.

Gross, Tuma, and de Treville (1971) studied at necropsy the lungs of 20 fibreglass workers, with past exposures ranging from 16 to 31 years. They compared their findings with those in a similar study of 26 urban dwellers with no known occupational exposure to fibreglass. Their conclusion was categorically stated: 'Long-term exposure to the dust of fibreglass used for insulation caused no demonstrable gross or microscopic pulmonary damage'.

Enterline and Henderson (1975) investigated 416 men retiring from six plants engaged in the manufacture of fibrous glass insulation during 1945-72. There was no evidence of an excess of respiratory cancer mortality when compared with white US citizens of a comparable age and during similar time intervals. No mesotheliomas were noted.

The American Conference of Governmental Industrial Hygienists classified fibrous glass as an inert material. The discussion above indicates that the evidence on the possibility of fibrous glass causing human occupational cancer is minimal, and is heavily outweighed by the evidence against it. The trend of evidence seems to point away from viewing fibreglass as a substance with any long-term occupational toxicity or public health hazard in humans, in spite of fears expressed in some quarters (Montague and Montague, 1974).

I am grateful to Dr A. J. Christophers for his help. The Chief Health Officer, Dr B. McCloskey has kindly given permission to publish the paper.

\section{References}

American Conference of Governmental Industrial Hygienists (1971). Documentation of the Threshold Limit Values for Substances in Workroom Air. Third Edition. Cincinatti, Ohio.

Enterline, P. and Henderson, V. (1975). The health of retired fibrous glass workers. Archives of Environmental Health, 30, 113-116.

Gross, P., Kaschak, M., Tolker, E., Babyak, M., and de Treville, T. (1970). Pulmonary reaction to high concentrations of fibrous glass dust. Archives of Environmental Health, 20, 696-671.

- Tuma, J., and de Treville, T.(1971). Lungs of workers exposed to fiber glass. Archives of Environmental Health, 23, 67-76.

Hill, J. W., Whitehead, W. S., Cameron, J. D., and Hedgecock, G. A. (1973). Glass fibres: absence of pulmonary hazard in production workers. British Journal of Industrial Medicine, 30, 174-179.

Montague, K. and Montague, P. (1974). Fiber glass. Environment, 16, 6-9.

Stanton, M. (1974). Fiber carcinogenesis: is asbestos the only hazard? Journal of National Cancer Institute, 52, 633-636.

- and Wrench, C. (1972). Mechanisms of mesothelioma induction with asbestos and fibre glass. Journal of National Cancer Institute, 48, 797-821.

Wright, G. W. (1968). Airborne fibrous glass particles. Chest roentgenograms of persons with prolonged exposure. Archives of Environmental Health, 16, 175-181.

Received for publication 8 July 1975

Accepted for publication 11 December 1975 